https://doi.org/10.52449/1857-4114.2021.37-1.10

CZU: 796.333:796.058.5

\title{
DEVELOPING THE CREATIVITY OF CHILDREN WHO PRACTICE RUGBY IN SPORTS SCHOOLS
}

\author{
Bulai Veaceslav ${ }^{1}$, ORCID: 0000-0003-2021-5896 \\ ${ }^{1}$ State University of Physical Education and Sport, Chisinau, Republic of Moldova
}

\begin{abstract}
Creativity is a priority direction of education systems and public policies, especially those of scientific research. In a modern, dynamic society, characterized by economic, political and cultural mobility, a flexible education is needed, oriented towards the formation and development of a creative personality in cultural-professional-ethical plan. In these conditions, it is necessary to correlate the concept of didactic creativity with that of creative learning. This context generates the need for a theoretical and praxiological educational pedagogical reform, oriented with priority towards the area of didactic creativity, especially in the methodological plan which is currently characterized by traditional methods.

Synectics, as a method of stimulating and developing creativity, proposed by us in research, creates this climate of creative learning of children in sports schools, facilitating the exploration of its methodological value (especially in team sports events, especially rugby).
\end{abstract}

Keywords: creativity development, sports school, rugby, personal motivation, children, synectics.

Introduction. An important desideratum of the national education system is the formation and development of a creative personality, able to cope with situations in modern sociocultural conditions. The Education Code no. 152/2014 of the Republic of Moldova created the legal premises for the transition from a unitary, ideologized, totalitarian education system to a variable, humanistic system that promotes the creative development of children [Education Code of the Republic of Moldova no. 152/2014 ]. Currently, there is no universally valid definition of the concept of "creativity", therefore, from a multitude of definitions, we aim to rely on the interpretation of the term "creativity" formulated by A.V. Petrovsky and M.G. Yaroshevsky, who mentioned that this concept "constitutes the level of creative giftedness, the ability to be creative, which is a relatively stable characteristic of a person" [6, p. 47]. We believe that this definition is the most appropriate in the research problem. According to several authors, one of the priority conditions for the development of creativity is the adoption of a legal framework specific to the educational environment, inherent in the microclimate of sports schools in Moldova. Within them we can identify a special educational development environment, which allows the efficient solution of complex personality development problems [2]. But, unfortunately, not all sports schools in Moldova aim at training and developing the child's creativity.

In the Republic of Moldova, according to statistical data of the NBS [National Bureau of Statistics (Physical Culture and Sports)], in the period 2009 - 2016 the education system of sports schools is developed on the basis of 86 
sports schools in 2009 and 92 in 2016 (Table 1). Among them are the specialized sports schools in the amount of 29, in 2009, and 32 in 2016, respectively. Regarding the issue addressed, it seems necessary to take into account the activities of sports schools for children and youth in the context of developing creativity.

Table 1. Number of sports schools in the Republic of Moldova (2009-2016)

\begin{tabular}{|c|c|c|c|c|c|c|c|c|}
\hline & 2009 & 2010 & 2011 & 2012 & 2013 & 2014 & 2015 & 2016 \\
\hline $\begin{array}{c}\text { Nr. sports schools } \\
\text { in the Republic of } \\
\text { Moldova }\end{array}$ & 86 & 86 & 86 & 89 & 89 & 91 & 92 & 92 \\
\hline Specialized & 29 & 31 & 34 & 34 & 32 & 32 & 32 & 32 \\
\hline
\end{tabular}

Specialized sports activities in sports schools have a number of health benefits, teaching children what discipline is, developing their personality and creating some opportunities for socializing and communicating with other active children. One of the most popular activities for children is sports $(25 \%$ of the total number of students in the national education system). In 2016, there were 92 sports schools in the education system, including 32 specialized sports schools.

The Specialized Sports School of Acrobatics and Rugby in Moldova is an educational institution for children of physical culture and sports orientation; is organized to carry out educational activities in rugby sports clubs, training young athletes, providing initial and basic training for specialization in this sport event. Given the definition of the term sports school, it should be noted that the training within it aims to educate a professional athlete with the potential to achieve high results. Therefore, training is based on physical activity, as well as on the formation / development of the children's sports component, without paying attention to other aspects of personality. But the level of results in modern sports requires the consolidation not only of a complex of physical but also mental qualities, which are at an extremely high level of their manifestation, in order to achieve performance.
As the level of sports achievements increases, so do the requirements for the mental activity of an athlete, whose integral component is the creative skills, which evolve more and more clearly. Thus, it can be argued that in the Specialized Sports School of Acrobatics and Rugby in Moldova (Chisinau) it can be argued that, in addition to basic sports training, it is necessary to develop students' creativity. The children who participate in the training process (preparation) are intentionally focused on a long and difficult educational path, with a focus on high sports achievements.

Therefore, such a complex physical and psychological process occupies most of the student's free time from sports school, leaving time to visit other extracurricular institutions, to develop versatile personality traits, respectively individual creativity.

The turning point in the development of systematic research on creativity was the 1950s, when J.P. Guilford, as president of the American Psychological Association, urged all psychologists to study especially how to stimulate and capitalize on creative potential. This is how the first methods of developing creativity appeared: brainstorming (a method founded by A. Osborn) and synectics (a method created by W. Gordon). Today, in the third millennium, creativity has come to be analyzed from a threefold perspective: psychological, social and pedagogical. 
This is the second reason for the need to develop students' creativity in sports schools. In addition, we draw attention to the affiliation of sports schools to extracurricular institutions, whose main objective is to develop personal motivation for learning and creativity, implementing additional educational programs and services in the interest of the individual, society and the state. Personal development has its origins in ancient philosophy: that attributed to Aristotle in Europe and the teachings of Confucius in Asia. If some wanted to discover the meaning of life and how you can be happy, others were a little more pragmatic. According to Michel Foucault in Self-Care, in ancient Greeks and Romans, personal development was called epimelia and consisted of diets, exercise, sexual abstinence, meditation, and prayer. Covering various areas, from understanding one's identity to developing latent talents, from improving living conditions to achieving dreams and aspirations, personal development contributes not only to the appearance of an individual, but also confers advantages over others in terms of career. Like a healthy lifestyle, personal development is a lifelong journey that stretches throughout life.

Thus, we determine the third reason why it is necessary to develop the creativity of students of sports schools in Moldova, as an integral part of extracurricular education institutions. The institution is obliged to develop the student's creative personality. The development of creativity in sports is dedicated to the works of A.A. Derkach and A.A. Isaev, 1981 [5]. But this problem has not been fully studied $[1,3]$.

Currently, in the Republic of Moldova there are youth sports schools for various sports events, such as: rugby, acrobatics, boxing, chess, table tennis, hockey, basketball, sports aerobics, volleyball, rhythmic gymnastics, orienteering, rowing, judo, Greco-Roman wrestling, fencing, karate, kickboxing, swimming, figure skating, sport dancing, athletics.
After analyzing the objectives of the School of Acrobatics and Rugby, we can highlight: creating favorable conditions for the harmonious development of the young generation, improving the quality of education and talents of children, adolescents, young people, and increasing the effectiveness of their creative potential. This mission indicates the presence of a creative factor in ensuring teaching to children involved in the training process.

Given the curriculum of several training groups for certain ages in the monitored school, we did not identify indicators to stimulate children's creativity. Thus, a contradiction was found in the discrepancy between the objectives of the activity of the Sports School of Acrobatics and Rugby and the training plans of the specific rugby groups. But this contradiction can be controversial, as, referring to the rugby sport, we can mention that it is in itself a means of developing children's creativity. Thus, we can say that, in the conditions of the sports school for youth, creativity is developed through creative methods (synectics), as it is important to emphasize the development of a versatile and creative personality of the child in the team, with which he will be able to get high results in competitions.

Because in rugby special attention is paid to physical training to improve the level of an athlete's skills, the program of training groups within the reference sports school does not include classes aimed at developing students' creativity, so necessary for them in modern society.

In this context, we identified three main reasons for the need to develop students' creativity in sports schools in Moldova, as follows:

- achieving the student's sports training, not paying attention to other aspects of the personality;

- playing a large part of a child's free time, which does not offer the opportunity to participate in other programs for personal 
development. The sports school is an educational institution that develops a person's motivation for knowledge and creativity;

- the lack of a methodology for developing students' creativity in sports schools.

In conclusion, we can mention that no attention is paid to the problems of developing the creativity of athletes in organizing the training process.

This negative factor is facilitated not only by the organization of sports school activities, but also by ensuring institutional management, which, on the one hand, does not oppose the process of developing athletes' creativity, on the other hand, does not contribute to its development. This explains the situation where we observe a limited number of hours provided for this purpose in the training plans. In order to educate a creative personality in sports schools, it is necessary to introduce a number of curricular hours, corresponding to the development of athletes' creativity, without disrupting the educational and training process. We also recommend the use of team games by the synectic method to implement the education of the creative personality of the athlete. For this, various methods can be studied, selected and adapted to identify the level of creativity of athletes at that time. These methods and tests can be performed with students on the proposed topic: "Creativity games", and with the help of Torrance's diagnostic battery can be planned and evaluated exercises (games) to develop the creativity of team athletes in accordance with established principles and rules. in methodical guidance in the direction of developing the area of creativity [4]. Subsequently, the tests can be repeated to identify the level of creativity and to compare the measurable indicators.

The results and conclusions of all tests and methods performed will be published in order to constantly highlight the data obtained. Thus, the introduction of different methods for developing children's creativity in one of the topics of the training plan will contribute to the development of an important quality creativity, which will lead to performance in the child's sports activity.

\section{References:} $380 \mathrm{p}$.

1. Agrigoroaie D. (2005). Educaюie pentru gвndire creatoare. Piatra Neamю: Ed. Alfa.

2. Amabile T. (1997). Creativitatea ca mod de viaюz. Bucureєti: Ed. Єtiinюг єi tehnicг. $364 \mathrm{p}$.

3. Călin M. (1996). Educarea creativităţii. Bucureşti.

4. Грецов А.Г. (2007). Тренинг креативности для старшекласников и студентов. Питер: 208 с.

5. Деркачь А.А., Исаев А.А. (1981). Педагогическое мастерство тренера. Москва: ФиС. 374 с.

6. Петровский А.В., Ярошевский М.Г. (1990). Психология. Словарь. 2-е изд., испр. и доп. Москва: Политиздат. 494 с. 